\title{
Blunted endogenous opioid release following an oral dexamphetamine challenge in abstinent alcohol-dependent individuals
}

\author{
Samuel Turton ${ }^{1} \cdot$ James FM Myers ${ }^{1} \cdot$ Inge Mick $^{1,2} \cdot$ Alessandro Colasanti $^{3,4} \cdot$ Ashwin Venkataraman $^{1} \cdot$ Claire Durant $^{1}$. \\ Adam Waldman $^{5} \cdot$ Alan Brailsford ${ }^{6} \cdot$ Mark C Parkin $^{6} \cdot$ Gemma Dawe $^{7} \cdot$ Eugenii A Rabiner $\mathbb{D}^{8,9} \cdot \operatorname{Roger} N$ Gunn $\mathbb{D}^{8,10}$. \\ Stafford L Lightman ${ }^{11} \cdot$ David J Nutt $\mathbb{1}^{1} \cdot$ Anne Lingford-Hughes ${ }^{1}$
}

Received: 21 September 2017 / Revised: 9 May 2018 / Accepted: 14 May 2018 / Published online: 25 June 2018

(c) The Author(s) 2018. This article is published with open access

\begin{abstract}
Addiction has been proposed as a 'reward deficient' state, which is compensated for with substance use. There is growing evidence of dysregulation in the opioid system, which plays a key role in reward, underpinning addiction. Low levels of endogenous opioids are implicated in vulnerability for developing alcohol dependence (AD) and high mu-opioid receptor (MOR) availability in early abstinence is associated with greater craving. This high MOR availability is proposed to be the target of opioid antagonist medication to prevent relapse. However, changes in endogenous opioid tone in AD are poorly characterised and are important to understand as opioid antagonists do not help everyone with $\mathrm{AD}$. We used $\left[{ }^{11} \mathrm{C}\right]$ carfentanil, a selective MOR agonist positron emission tomography (PET) radioligand, to investigate endogenous opioid tone in $\mathrm{AD}$ for the first time. We recruited 13 abstinent male $\mathrm{AD}$ and 15 control participants who underwent two $\left[{ }^{11} \mathrm{C}\right]$ carfentanil PET scans, one before and one $3 \mathrm{~h}$ following a $0.5 \mathrm{mg} / \mathrm{kg}$ oral dose of dexamphetamine to measure baseline MOR availability and endogenous opioid release. We found significantly blunted dexamphetamine-induced opioid release in 5 out of 10 regionsof-interest including insula, frontal lobe and putamen in AD compared with controls, but no significantly higher MOR availability AD participants compared with $\mathrm{HC}$ in any region. This study is comparable to our previous results of blunted dexamphetamine-induced opioid release in gambling disorder, suggesting that this dysregulation in opioid tone is common to both behavioural and substance addictions.
\end{abstract}

Electronic supplementary material The online version of this article (https://doi.org/10.1038/s41380-018-0107-4) contains supplementary material, which is available to authorised users.

Anne Lingford-Hughes

anne.lingford-hughes@imperial.ac.uk

1 Neuropsychopharmacology Unit, Centre for Psychiatry, Imperial College London, London, UK

2 Institute for Clinical Teratology and Drug Risk Assessment in Pregnancy, Charité Universitätsmedizin, Berlin, Germany

3 Department of Neuroscience, Brighton and Sussex Medical School, University of Sussex, Brighton, UK

4 Centre for Affective Disorders, Institute of Psychiatry, Psychology and Neuroscience, King's College London, London, UK

5 Centre for Clinical Brain Sciences, University of Edinburgh, Edinburgh, UK

\section{Introduction}

Alcohol dependence (AD) affects $4 \%$ of adults in Europe and $4.7 \%$ in the United States, and globally 3.3 million deaths per year (5.9\% of deaths worldwide) are attributed to

6 Analytical and Environmental Sciences, King's College London, London, UK

7 Department of Neuroradiology, Imperial College Healthcare NHS Trust, London, UK

8 Imanova Limited, London, UK

9 Centre for Neuroimaging Sciences, King's College London, London, UK

10 Centre for Restorative Neuroscience, Division of Brain Sciences, Imperial College London, London, UK

11 Henry Wellcome Laboratories for Integrative Neuroscience \& Endocrinology, University of Bristol, Bristol, UK 
harmful alcohol use [1]. Treatment for alcohol abuse and dependence costs an estimated $\$ 12$ billion in the US and €5 billion in the EU [2, 3], however three quarters of individuals with $\mathrm{AD}$ will not remain abstinent from alcohol in the first year following treatment [4]. Thus, there is a substantial unmet need in reducing this harm.

Psychosocial approaches are the mainstay treatment of $\mathrm{AD}$ but effective relapse prevention medications, including the opioid antagonists naltrexone and nalmefene, are available [5-7]. Opioid antagonists modulate the mesolimbic 'reward' pathway, which is proposed to underpin their effectiveness in reducing the risk of relapse to heavy drinking [5, 7-9]. Using functional magnetic resonance imaging (fMRI), naltrexone and nalmefene have been shown to reduce brain responses in the mesolimbic pathway to salient alcohol cues or exposure [10, 11]. These medications do not help everyone and so a better understanding of opioid system function in alcoholism is required to develop improved therapies and better target individuals with current medication.

The mu-opioid receptor (MOR) subtype is expressed in brain regions associated with addiction including the ventral tegmental area, nucleus accumbens and amygdala. The MOR and its endogenous ligands, including $\beta$-endorphin, play an important role in reward [12-14]. Some substances of abuse, including alcohol and amphetamines, increase the levels of endogenous opioids binding to MORs and this is associated with positive subjective effects, including 'best ever' feelings and euphoria $[15,16]$. Naltrexone has been shown to attenuate these positive subjective effects [17-19]. Endogenous opioid dysregulation may also play an important role in the vulnerability to developing addiction where a 'reward deficient' state leads to substance abuse to compensate for opioidergic hypofunction [20, 21].

Lower basal endogenous opioid levels in the brain may result in higher opioid receptor availability and this has been demonstrated in $\mathrm{AD}$ during early abstinence using the non-selective radioligand $\left[{ }^{11} \mathrm{C}\right]$ diprenorphine [22] and the MOR-selective radioligand $\left[{ }^{11} \mathrm{C}\right]$ carfentanil $[23,24]$. Higher opioid receptor availability is associated with alcohol craving $[22,23,25]$ and alcohol-dependent individuals with higher $\left[{ }^{11} \mathrm{C}\right]$ carfentanil binding may benefit more from naltrexone treatment [25]. This suggests that the effectiveness of opioid antagonists is linked to opioid receptor availability in humans. However, no studies have assessed in vivo endogenous opioid tone in $\mathrm{AD}$, which is also key to understanding the predictors of response to opioid antagonists.

We have developed and validated a $\left[{ }^{11} \mathrm{C}\right]$ carfentanil positron emission tomography (PET) protocol to assess endogenous opioid release following an oral dexamphetamine challenge $[15,26]$. With this protocol, we demonstrated no difference in baseline MOR availability but a blunted dexamphetamine-induced opioid release, with blunted associated subjective effects, in gambling disorder [27]. In this study, we applied the same protocol to test the hypotheses that in $\mathrm{AD}$ there is blunted dexamphetamine-induced endogenous opioid release, as shown in gambling disorder, and a higher baseline MOR availability.

\section{Patients and methods}

This study was approved by the West London Research Ethics Committee and the Administration of Radioactive Substances Advisory Committee, UK (14/LO/1552). Written informed consent was obtained from all the participants.

Alcohol-dependent (AD) men $(n=13,>4$ weeks abstinent, DSM-5 criteria for 'severe' alcohol use disorder) were recruited from Central North West London NHS Foundation Trust, UK and associated services. Severity of AD, relapse risk and alcohol craving were assessed using the Severity of Alcohol Dependence Questionnaire (SADQ) [28], Time to Relapse Questionnaire (TRQ) [29] and Alcohol Urge Questionnaire (AUQ) [30]. 'High risk' alcohol exposure was calculated as lifetime cumulative weeks with $>60 \mathrm{~g}$ average daily alcohol consumption [31]. Male healthy controls (HC) $(n=15)$ included 10 from previous studies $[15,26]$ and 5 recruited for the current study to achieve age-matching between groups.

All participants' physical and mental health history, including history of alcohol, tobacco and substance use, was assessed by psychiatrists using the Mini International Neuropsychiatric Interview (MINI-5) [32]. Current or past history of gambling disorder or substance dependence (excluding nicotine) was an exclusion criterion; previous recreational drug use was allowed ( $>10$ times in lifetime: cannabis: $3 \mathrm{HC}, 9 \mathrm{AD}$, cocaine: $6 \mathrm{AD}$, stimulants: $5 \mathrm{AD}$, inhalants: $1 \mathrm{HC}, 3 \mathrm{AD}$, hallucinogens: $1 \mathrm{AD}$, sedatives: $1 \mathrm{AD}, 2 \mathrm{HC}$, opioids: $1 \mathrm{AD})$. HC were excluded if they drank $>21$ UK units of alcohol $(166 \mathrm{~g})$ per week or had a previous history of AD. Drug use (except nicotine) was not permitted 2 weeks prior to the study visits and confirmed by negative urine drug screen (cocaine, amphetamine, THC, methadone, opioids, benzodiazepines). Participants were breathalysed for alcohol. Smoking tobacco was not allowed $1 \mathrm{~h}$ before each scan. All participants had laboratory and ECG results within normal range, and were not prescribed any regular psychotropic medications.

Participants with current or previous psychiatric disorders were excluded. However, in AD participants a past history of depression (non-psychotic) and/or anxiety disorders was permitted owing to the high prevalence in this population. Depression was assessed with the Beck Depression Inventory (BDI) [33] and anxiety with 
Spielberger State/Trait Inventory (SSAI and STAI) [34]. Impulsivity was assessed with the UPPS-P Impulsive Behaviour Scale [35].

\section{Genotyping}

Blood samples for genotyping of OPRM1 A118G polymorphism were available from all participants (AD: $n=13$; HC: $n=11$ ) except for four HC from our first study [15] and were analysed by LGC Limited (Middlesex, UK). DNA was extracted and normalised and underwent SNP-specific $\mathrm{KASP}^{\mathrm{TM}}$ Assay mix. Loci with a call rate $<90 \%$ were not included. Participants were categorised as a G-allele carrier (G:A or $G: G)$ or not (A:A).

\section{PET and MR imaging protocol}

We followed our protocol as previously described $[15,26,27] .\left[{ }^{11} \mathrm{C}\right]$ carfentanil PET scans were acquired on a HiRez Biograph six PET/CT scanner (Siemens Healthcare, Erlangen, Germany). Dynamic emission data were collected continuously for $90 \mathrm{~min}$ ( 26 frames, $8 \times 15 \mathrm{~s}, 3 \times 60 \mathrm{~s}, 5 \times$ $120 \mathrm{~s}, 5 \times 300 \mathrm{~s}, 5 \times 600 \mathrm{~s}$ ) following an intravenous bolus infusion of maximum $350 \mathrm{MBq}\left[{ }^{11} \mathrm{C}\right]$ carfentanil infused over $20 \mathrm{sec}$. Participants underwent two $\left[{ }^{11} \mathrm{C}\right]$ carfentanil PET scans, one before and one $3 \mathrm{~h}$ following the oral administration of $0.5 \mathrm{mg} / \mathrm{kg}$ dexamphetamine. Seven participants ( $n=1 \mathrm{AD}, n=7 \mathrm{HV}$ ) underwent scans on separate days. However, there were no significant effects of this on $\left[{ }^{11} \mathrm{C}\right]$ carfentanil binding potential $\left(\mathrm{BP}_{\mathrm{ND}}\right)$.

Subjective responses to dexamphetamine challenge were measured with the Simplified Amphetamine Interview Rating Scale (SAIRS) (15 mins pre-dose (baseline), 1, 2, 3, $4.5 \mathrm{~h}$ post dose) [36], and SSAI (before and after each PET scan).

Blood samples to measure plasma dexamphetamine levels were obtained pre dose (baseline), 1, 2, 3 and $4.5 \mathrm{~h}$ post dosing. Dexamphetamine samples were analysed at the Drug Control Centre, Analytical and Environmental Sciences, King's College London, UK. Serum cortisol samples were collected immediately pre-dexamphetamine dose (baseline), 30, 60, 90, 120, 150 and $180 \mathrm{~min}$ post dose. Cortisol samples were analysed using the ARCHITECT cortisol assay at the Pathology Department, Hammersmith Hospital, Imperial College Healthcare NHS Trust, London, UK. See Supplementary data for further details of cortisol and amphetamine assays.

On a different day to their PET scans, participants underwent a T1-weighted structural MRI (Magnetom Trio Syngo MR B13 Siemens 3 T; Siemens AG, Medical Solutions). Subjects completed the ICCAM fMRI imaging platform [37, 38] and these results will be reported elsewhere.

\section{Image analysis}

As described previously [15, 26, 27], image pre-processing and PET modelling were carried out using MIAKAT (www. miakat.org). Dynamic PET data underwent motion correction and rigid-body coregistration to the structural MRI. Ten bilateral regions of interest were chosen a priori: caudate, putamen, thalamus, cerebellum grey matter, frontal lobe grey matter, nucleus accumbens, anterior cingulate, amygdala, insular cortex and hypothalamus. All time-activity data, except the hypothalamus, were sampled using a neuroanatomical atlas [39]. This was applied to the PET image by nonlinear deformation parameters derived using unified segmentation (SPM-12) of the structural MRI. The template and atlas fits were confirmed visually for each participant. The hypothalamus was manually defined on individual structural MRIs as previously described $[15,39]$.

$\left[{ }^{11} \mathrm{C}\right]$ carfentanil $\mathrm{BP}_{\mathrm{ND}}$ values were quantified using the simplified reference tissue model with occipital lobe as the reference region $[15,40] . \mathrm{BP}_{\mathrm{ND}}$ is the ratio of specifically bound radioligand (e.g., bound to MOR) to that of nondisplaceable radioligand (e.g., unbound and non-specifically or non-MOR bound $\left[{ }^{11} \mathrm{C}\right]$ carfentanil) in tissue at equilibrium. $\mathrm{BP}_{\mathrm{ND}}$ used in reference tissue methods compares the concentration of radioligand in receptor-rich with receptorfree regions [41]. Reductions in $\left[{ }^{11} \mathrm{C}\right]$ carfentanil $\mathrm{BP}_{\mathrm{ND}}$ observed following dexamphetamine challenge are owing to reductions in specific $\left[{ }^{11} \mathrm{C}\right]$ carfentanil binding to MORs associated with endogenous opioid release, compared with non-specific $\left[{ }^{11} \mathrm{C}\right]$ carfentanil binding in the occipital lobe reference region. Endogenous opioid release was indexed as the fractional reduction in $\left[{ }^{11} \mathrm{C}\right]$ carfentanil $\mathrm{BP}_{\mathrm{ND}}$ following dexamphetamine:

$$
\Delta B P_{N D}=\frac{\left(B P_{N D p o s t}-B P_{N D p r e}\right)}{B P_{N D p r e}}
$$

\section{Statistical analysis}

All statistical analyses were carried out using IBM SPSS (version 24). Data were normally distributed (Shapiro-Wilk) except for BDI and abstinence duration.

Demographic differences between groups were assessed using independent sample $t$ tests. Omnibus mixed-model analysis of variance (ANOVA) tested the effects of status (AD or $\mathrm{HC}$ ) on $\left[{ }^{11} \mathrm{C}\right]$ carfentanil $\mathrm{BP}_{\mathrm{ND}}$ and $\triangle \mathrm{BP}_{\mathrm{ND}}$, SAIRS and SSAI subjective responses, plasma amphetamine and serum cortisol concentrations. Post hoc tests were made using one-way ANOVA or $t$ tests. Correlational analyses were made using Pearson correlation coefficient or Spearman's rho (BDI and abstinence duration). Bonferroni corrected $p$ values are reported in the results. Data were tested 
Table 1 Demographic and genotype data $($ mean $\pm \mathrm{SD})$

\begin{tabular}{llll}
\hline & Healthy controls & Alcohol dependence & $p$ value (two-tailed) \\
\hline Numbers & 15 & 13 & \\
Age & $42.8( \pm 10.2)$ & $46.6( \pm 7.3)$ & 0.281 \\
IQ & $115.6( \pm 9.9)$ & $107.8(+10.7)$ & 0.090 \\
Alcohol UK units/week & $6.67( \pm 8.2)$ & 0 & \\
Current smokers & 3 & 7 & \\
Cigarettes per day (current smokers) & $10.0( \pm 5.0)$ & $10.6( \pm 7.7)$ & 0.247 \\
Pack years (current and ex-smokers) & $7.9( \pm 8.1)$ & $23.6( \pm 14.5)$ & 0.063 \\
FTND (current smokers) & $3.0( \pm 2.7)$ & $3.7( \pm 3.1)$ & 0.906 \\
BDI on PET visit & $0.2( \pm 0.6)$ & $3.3( \pm 3.6)$ & $\mathbf{0 . 0 0 4}$ \\
STAI & $30.3( \pm 7.4)$ & $37.2( \pm 5.9)$ & $\mathbf{0 . 0 1 2}$ \\
SSAI (before PET 1) & $27.9( \pm 6.6)$ & $28.8( \pm 9.9)$ & 0.797 \\
UPPS-negative urgency & $20.8( \pm 6.1)$ & $27.4( \pm 4.1)$ & $\mathbf{0 . 0 0 6}$ \\
SADQ & & $38.5( \pm 11.2)$ & \\
TRQ & $9.6( \pm 12.7)$ & $604.6( \pm 866.5)$ & $<\mathbf{0 . 0 0 1}$ \\
Alcohol abstinence (days) & 2 of $11(18.2 \%)$ & 4 of $13(30.1 \%)$ & \\
OPRM1 G-allele carrier &
\end{tabular}

Abbreviations: FTND Fagerstrom Test for Nicotine Dependence, BDI Beck Depression Inventory, SSAI, STAI Spielberger State and Trait Anxiety Inventory, UPPS Impulsivity Scale, SADQ Severity of Alcohol Dependence Questionnaire, TRQ Time to Relapse Questionnaire for sphericity, and where sphericity was violated ANOVAs were Greenhouse-Geisser corrected.

\section{Results}

\section{Demographic and clinical variables}

Demographic results are presented in Table 1. There were no significant differences in age or IQ between $\mathrm{HC}$ and $\mathrm{AD}$ participants. More AD participants smoked tobacco but there were no differences between daily numbers of cigarettes or dependence scores (FTND) between HC and AD smokers. AD participants had significantly higher BDI and STAI scores than HC but none reached a threshold for clinical anxiety or depression. UPPS-P negative urgency scores were higher in AD participants compared with HC.

\section{Injected mass and radioactivity and head motion}

There were no significant differences in injected cold carfentanil mass between AD participants and $\mathrm{HC}$ for either scan, but there was a significantly higher injected activity in post-dexamphetamine scans in AD participants (Supplementary Table 1). There were no significant correlations between $\left[{ }^{11} \mathrm{C}\right]$ carfentanil $\mathrm{BP}_{\mathrm{ND}}$ in any region and injected mass or activity in the pre- or post-dexamphetamine scans. There was no significant effect of dexamphetamine on movement within scans, or differences between $\mathrm{AD}$ and $\mathrm{HC}$ participants (Supplementary Tables 2 and 3).

\section{Dexamphetamine and cortisol pharmacokinetics}

A repeated measures ANOVA showed a significant effect of Time on dexamphetamine plasma concentrations but no significant effect of Status (AD or HC) (Supplementary Figure 4, Supplementary Table 5).

Serum cortisol concentration increased following oral dexamphetamine administration (Supplementary Figure 6). A mixed-model ANOVA showed a significant effect of Time on cortisol levels but no significant effect of Status (AD or HC) (Supplementary Table 5).

\section{Subjective effects of amphetamine}

The subjective effects from the oral dexamphetamine were mild in both groups (Fig. 1). A mixed-model ANOVA showed no significant effects of Time or Status (AD or HC) on changes in SAIRS scores from baseline (Supplementary Table 7). There was a significant Time $\times$ Status interaction on change in SAIRS Anxiety from baseline. Post hoc analysis (paired $t$ test) showed reductions in anxiety ratings in $\mathrm{HC}$ at 180 and 270 mins post-dexamphetamine $(p=0.048$ and $p=0.025$, respectively, Bonferroni corrected $p<0.01$ ), which was not present in the AD group. There was no significant effect of Time or Status on SSAI scores.

\section{Pre- and post-dexamphetamine $\left[{ }^{11} \mathrm{C}\right]$ carfentanil $\mathrm{BP} \mathrm{ND}_{\mathrm{ND}}$}

A mixed-model ANOVA examining pre- and postdexamphetamine $\left[{ }^{11} \mathrm{C}\right]$ carfentanil $\mathrm{BP}_{\mathrm{ND}}$ showed a significant 

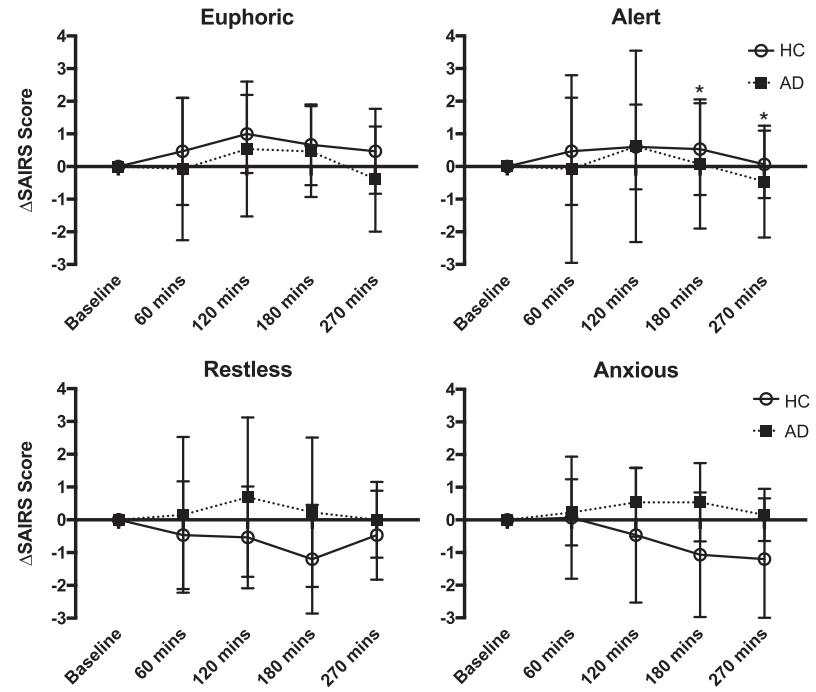

Fig. 1 Change in SAIRS following dexamphetamine administration (mean $\pm \mathrm{SD}, * p<0.05$ in $\mathrm{HC}$ )

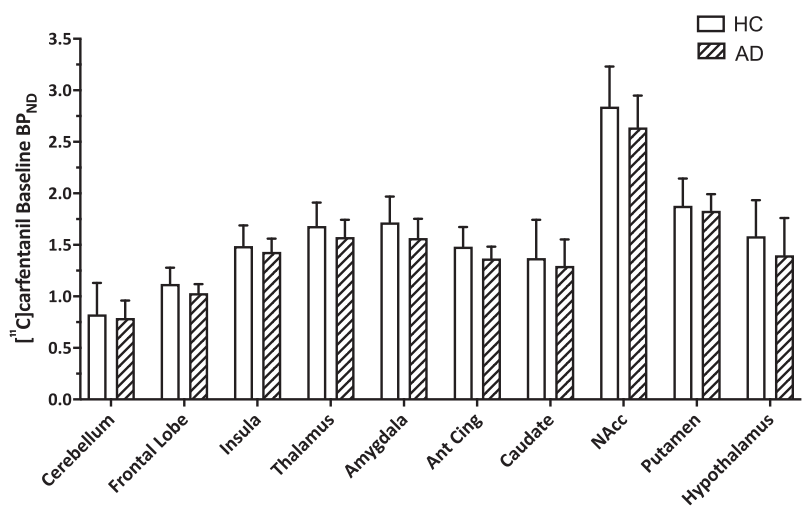

Fig. 2 Baseline $\left[{ }^{11} \mathrm{C}\right]$ carfentanil $\mathrm{BP}_{\mathrm{ND}}$ in $\mathrm{HC}$ and $\mathrm{AD}$ participants $($ mean $\pm \mathrm{SD})$

effect of Scan (pre- or post-dexamphetamine) demonstrating differences in $\mathrm{BP}_{\mathrm{ND}}$ following dexamphetamine, and a significant Scan $\times$ Status interaction indicating a significantly different change in $\mathrm{BP}_{\mathrm{ND}}$ after dexamphetamine between $\mathrm{AD}$ and HC (Supplementary Table 8). Post hoc paired $t$ tests showed significant reductions in $\mathrm{BP}_{\mathrm{ND}}$ after oral dexamphetamine in $\mathrm{HC}$ across all ROIs except hypothalamus and amygdala, but no significant reductions in AD participants (Supplementary Table 9).

A mixed-model ANOVA examining pre-dexamphetamine $\left[{ }^{11} \mathrm{C}\right]$ carfentanil $\mathrm{BP}_{\mathrm{ND}}$ showed no significant effect of Status indicating no differences between $\mathrm{AD}$ and $\mathrm{HC}$ participants (Fig. 2, Supplementary Tables 8 and 9).

A mixed-model ANOVA examining $\left[{ }^{11} \mathrm{C}\right]$ carfentanil $\triangle \mathrm{BP}_{\mathrm{ND}}$ showed a significant effect of Status, indicating differences between $\mathrm{AD}$ and $\mathrm{HC}$ participants. Independent sample $t$ tests showed $\left[{ }^{11} \mathrm{C}\right]$ carfentanil $\Delta \mathrm{BP}_{\mathrm{ND}}$ (i.e., opioid release) was significantly blunted in $\mathrm{AD}$ participants, compared with $\mathrm{HC}$, in the frontal lobe, insula, thalamus, anterior cingulate and putamen (Bonferroni corrected $p<0.005$ ) with large effect sizes (Cohen's $\mathrm{D}>0.8$, significant $t$ tests comparing $\left[{ }^{11} \mathrm{C}\right]$ carfentanil $\Delta \mathrm{BP}_{\mathrm{ND}}$ between $\mathrm{HC}$ and $\mathrm{AD}$ ) (Figs. 3 and 4, Supplementary Tables 8 and 9).

\section{$\left[{ }^{11} \mathrm{C}\right]$ carfentanil binding, demographic and clinical variables}

We found no significant correlations between $\left[{ }^{11} \mathrm{C}\right]$ carfentanil $\mathrm{BP}_{\mathrm{ND}}$ and $\triangle \mathrm{BP}_{\mathrm{ND}}$ with $\mathrm{SADQ}$, TRQ, duration/length of alcohol abstinence or exposure measures in $\mathrm{AD}$ participants. Of note, AD did not report any AUQ craving at baseline or at any other point during the study. There were no significant differences in $\left[{ }^{11} \mathrm{C}\right]$ carfentanil $\mathrm{BP}_{\mathrm{ND}}$ or $\Delta \mathrm{BP}_{\mathrm{ND}}$ comparing smokers with non-smokers regardless of group (combined $\mathrm{AD}$ and $\mathrm{HC}$ or $\mathrm{AD}$ and $\mathrm{HC}$ separately). The inclusion of smoking status in the mixed-model ANOVA examining $\left[{ }^{11} \mathrm{C}\right]$ carfentanil $\Delta \mathrm{BP}_{\mathrm{ND}}$ did not impact on these results (Supplementary Table 8). There were no significant correlations between $\left[{ }^{11} \mathrm{C}\right]$ carfentanil $\mathrm{BP}_{\mathrm{ND}}$ or $\triangle \mathrm{BP}_{\mathrm{ND}}$ with daily cigarettes smoked or FTND scores in all participants ( $\mathrm{AD}$ and $\mathrm{HC}$ ) or $\mathrm{AD}$ or $\mathrm{HC}$ separately.

There was no significant association between UPPS-P negative urgency and baseline $\left[{ }^{11} \mathrm{C}\right]$ carfentanil $\mathrm{BP}_{\mathrm{ND}}$ in $\mathrm{AD}$ or HC participants. There was a significant positive correlation between $\left[{ }^{11} \mathrm{C}\right]$ carfentanil $\triangle \mathrm{BP}_{\mathrm{ND}}$ in the amygdala and BDI score (Spearman's rho $=0.654, p=0.015$ ) in $\mathrm{AD}$ only, indicating a higher BDI score is associated with lower opioid release. This result did not survive Bonferroni correction (two-tailed $p<0.005$ ). There were no correlations between STAI and $\left[{ }^{11} \mathrm{C}\right]$ carfentanil $\mathrm{BP}_{\mathrm{ND}}$ or $\Delta \mathrm{BP}_{\mathrm{ND}}$ in either participant group.

\section{MOR polymorphism}

There was a higher G-allele prevalence in AD participants compared with HC (30.1 and $18.2 \%$ respectively-, Table 1). To assess the influence of the OPRM1 A118G polymorphism on $\left[{ }^{11} \mathrm{C}\right]$ carfentanil $\mathrm{BP}_{\mathrm{ND}}$ the two mixedmodel ANOVAs examining $\left[{ }^{11} \mathrm{C}\right]$ carfentanil $\mathrm{BP}_{\mathrm{ND}}$ and $\triangle \mathrm{BP}_{\mathrm{ND}}$ were repeated with the addition of the genotype (A: A or $A: G / G: G)$ as a between-subject factor.

We found a significant main effect of Genotype on baseline $\left[{ }^{11} \mathrm{C}\right]$ carfentanil $\mathrm{BP}_{\mathrm{ND}}$, but no Status $\times$ Genotype interaction. A post hoc analysis independent sample $t$ test showed significantly lower $\left[{ }^{11} \mathrm{C}\right]$ carfentanil $\mathrm{BP}_{\mathrm{ND}}$ in $\mathrm{G}$ allele carriers in the thalamus (two-tailed Bonferroni corrected $p<0.005)$, and a trend toward lower $\left[{ }^{11} \mathrm{C}\right]$ carfentanil $\mathrm{BP}_{\mathrm{ND}}$ across all other regions (Supplementary Figure 10, Tables 11 and 12). We found no significant main effect of 


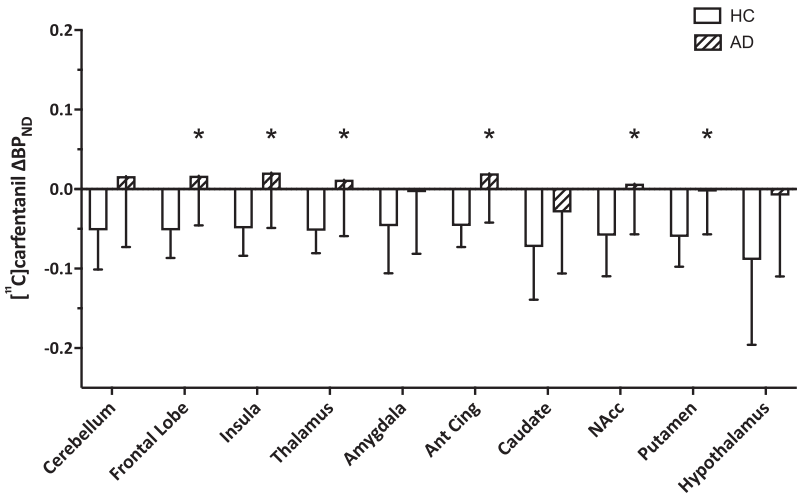

Fig. $3\left[{ }^{11} \mathrm{C}\right]$ carfentanil $\Delta \mathrm{BP}_{\mathrm{ND}}$ in $\mathrm{HC}$ and $\mathrm{AD}$ participants (mean $\pm \mathrm{SD}$, *significant $\triangle \mathrm{BP}_{\mathrm{ND}}$ differences between $\mathrm{HC}$ and $\mathrm{AD}$, Bonferroni corrected $p<0.005$ )

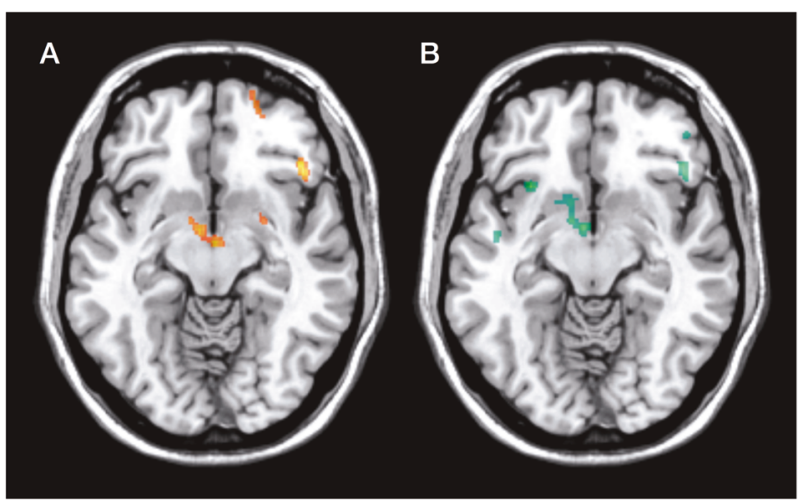

Fig. 4 a Clusters with significant reductions in $\left[{ }^{11} \mathrm{C}\right]$ carfentanil $\mathrm{BP}_{\mathrm{ND}}$ following dexamphetamine in $\mathrm{HC}$. There are no significant clusters in $\mathrm{AD}$. b Clusters with significantly lower $\left[{ }^{11} \mathrm{C}\right]$ carfentanil $\triangle \mathrm{BP}_{\mathrm{ND}}$ in $\mathrm{AD}$ compared with $\mathrm{HC}$ (all images: min cluster size 100, $p<0.001, \mathrm{z}=62$ )

Genotype or Status x Genotype interaction on $\left[{ }^{11} \mathrm{C}\right]$ carfentanil $\Delta \mathrm{BP}_{\mathrm{ND}}$.

\section{Discussion}

We have demonstrated a blunted dexamphetamine-induced endogenous opioid release in the brain for the first time in abstinent alcohol-dependent individuals with $\left[{ }^{11} \mathrm{C}\right]$ carfentanil PET. We did not find higher baseline MOR availability in $\mathrm{AD}$ as previously reported by ourselves and others $[22,23,42]$. Our data in AD are consistent with our previous study in gambling disorder where we also found blunted dexamphetamine-induced opioid release [27]. This strongly suggests that dysregulation of opioid tone underpins both behavioural and substance addictions.

This 'opioid deficient' state may play a key role in a broader 'reward deficient' state associated with the development and maintenance of $\mathrm{AD}$ and other addictions, and may precede the development of addiction
[20, 21, 27, 43-45]. Individuals with AD or a family history of $\mathrm{AD}$ both have blunted responses to financial rewards and lower peripheral plasma $\beta$-endorphin concentrations [43, $44,46]$. Although peripheral and central $\beta$-endorphin are not directly comparable, both are produced from the cleavage of pro-opiomelanocortin (POMC) and the release of both can be stimulated by intense exercise, dexamphetamine and alcohol [15, 16, 46-49]. This low opioidergic function may represent a vulnerability to the development of addiction, which endures after successful treatment and may predispose an individual to relapse. There may be an additional impact of addiction or heavy alcohol use on endogenous opioid tone, though this is difficult to determine from our current $\left[{ }^{11} \mathrm{C}\right]$ carfentanil PET studies.

There is evidence of blunted intravenous dexamphetamineinduced dopamine release in $\mathrm{AD}$ during early abstinence [50], which may be a mechanism for the blunted dexamphetamineinduced endogenous opioid release AD. Another study reported that lower dexamphetamine-induced ventral striatal dopamine release was associated with blunted cortisol release [51]. However, in our alcohol-dependent participants, dexamphetamine-induced cortisol release was not blunted compared with controls. This may suggest that dopamine responses to dexamphetamine are less blunted in our alcoholdependent participants, with longer durations of abstinence, than those described in early abstinence [50].

The blunted dexamphetamine-induced endogenous opioid release in AD may be mediated by a mechanism downstream from dopamine release, which would be consistent with the findings of blunted endogenous opioid release in gambling disorder despite a higher dopamine response to oral dexamphetamine [27, 52]. Intravenous dexamphetamine increases striatal dopamine concentrations in man within minutes of administration [50, 53, 54] but does not result in similarly acute changes in opioid levels in the brain [55]. A period of $1.5-3 \mathrm{~h}$ following dexamphetamine administration is required to reach peak endogenous opioid concentrations [15, 26, 27, 56, 57], suggesting that the mechanism of dexamphetamine-induced endogenous opioid release is also downstream of the acute dopamine release. Concentrations of other monoamines (5HT and noradrenaline) are also increased by dexamphetamine, and may play a role in endogenous opioid release in brain regions with lower dopamine transporter density, such as the frontal cortex and thalamus [15, 58]. Further work is required to better understand the mechanisms of dexamphetamine-induced endogenous opioid release, and how this is blunted in both $\mathrm{AD}$ and gambling disorder.

The salience of our dexamphetamine 'reward' may also be a factor in mediating endogenous opioid release. As addiction develops, salience towards addiction-associated 
cues increases, whereas responses to non-addiction related rewards decrease $[59,60]$. For example, individuals with $\mathrm{AD}$ have blunted fMRI responses to non-salient financial rewards and higher responses to salient alcohol cues [43, 44, 61-63]. The effect of opioid antagonists to modulate the mesolimbic system also appears to be mediated by the salience of the reward. For example, naltrexone only blunts dexamphetamine-induced striatal dopamine release in rats following a period of dexamphetamine sensitisation [54]. Whereas naltrexone does not modulate striatal fMRI response to financial reward anticipation in $\mathrm{AD}$ [43], when the same task was performed during an alcohol infusion, a salient context, nalmefene reduces activation [11]. Naltrexone also reduces BOLD response in striatum to salient alcohol cues in alcohol-dependent individuals [10, 64]. This salience mediated endogenous opioid release, rather than low opioidergic tone, may the target for opioid receptor antagonists in reducing the risk of relapse to heavy drinking during abstinence.

Although the above evidence suggests that salience is an important factor for the activation of endogenous opioidergic signalling, a recent study has shown that feeding induces a release of endogenous opioids regardless of how palatable or 'rewarding' the food is [65]. One potential further study to elucidate the effect of the salience of a reward on endogenous opioid release in $\mathrm{AD}$ would be the administration of an alcohol challenge, where a non-blunted, or possibly enhanced, endogenous opioid release might be observed. However, this would not be an ethical experiment to conduct in our abstinent alcohol-dependent participants.

Contrary to our hypothesis we did not find higher MOR availability in alcohol-dependent participants compared with controls. Previous studies using $\left[{ }^{11} \mathrm{C}\right]$ carfentanil and $\left[{ }^{11} \mathrm{C}\right]$ diprenorphine have shown higher MOR in $\mathrm{AD}$, whereas in our data there were no evidence of higher MOR availability in our alcohol-dependent participants (Fig. 2, Supplementary Table 9) [22-24]. Hermann et al. [25] reported non-significantly higher $\left[{ }^{11} \mathrm{C}\right]$ carfentanil binding in recently abstinent alcohol-dependent individuals and lower MOR receptor numbers in post-mortem alcohol-dependent brains measured with the MOR agonist $\left[{ }^{3} \mathrm{H}\right] \mathrm{DAMGO}$. They proposed that repeated alcohol administration in $\mathrm{AD}$, and the subsequent chronic elevations in endogenous opioids, may lead to a compensatory reduction in absolute MOR numbers [25]. Chronic alcohol-induced endogenous opioid release may also lower basal endogenous opioid tone via homoeostatic feedback mechanisms, potentially through an inhibition of POMC activity [66]. This low endogenous tone, when coupled with a cessation of alcohol-induced opioid release, may lead to a relative increase in MOR availability in early abstinence, despite lower absolute MOR density.
It is unclear if there are changes in basal endogenous opioid tone or MOR receptor numbers as abstinence lengthens. Alcohol-dependent participants in our current study have a considerably longer abstinence compared with previous studies (months compared with days to weeks) [22-24] and have 'normal' MOR availability. This would be consistent with a 'normalisation' of the balance of MORs and endogenous opioid ligands as abstinence progresses. However, we did not observe any association between duration of abstinence and MOR availability in our current study and we and others have reported no changes in MOR or other opioid receptor availability in $\mathrm{AD}$ during the first 3 months of abstinence [22, 23]. Higher MOR availability associated with higher craving reported previously in $\mathrm{AD}$ may represent a greater potential to relapse, and a potential target for opioid receptor antagonist treatment. The lack of higher MOR availability in our alcohol-dependent participants may reflect their stable abstinence and low craving, and suggests these individuals may benefit less from opioid receptor antagonist treatment compared with recently abstinent individuals reporting high alcohol craving.

We explored a number of clinical variables that may influence $\left[{ }^{11} \mathrm{C}\right]$ carfentanil binding. Although smoking status differed in our alcohol-dependent and control groups, there was no influence of current smoking, or associated measures, on baseline MOR availability, or dexamphetamineinduced endogenous opioid release. Previous evidence concerning MOR in smokers is inconsistent, with higher, lower, or no differences in availability compared with nonsmokers reported [67-69]. Consistent with others, we found that OPRM1 G-allele carriers had lower MOR availability [70, 71]. We found no significant effect of the OPRM1 polymorphism on dexamphetamine-induced endogenous opioid release, whereas others have observed lower endogenous opioid release in G-allele carriers during a pain task following placebo administration [71]. In gambling disorder, we demonstrated a positive correlation between the UPPS-P negative urgency and baseline MOR availability in the caudate [27] but we did not replicate this finding in our alcohol-dependent group. This is consistent with previous evidence showing correlations between impulsivity and $\left[{ }^{11} \mathrm{C}\right]$ raclopride (D2/3) and $\left[{ }^{11} \mathrm{C}\right]-(+)-$ PHNO $\left(\mathrm{D}_{3}\right.$-preferring) in gambling disorder and cocaine dependence but no such correlations between $\left[{ }^{11} \mathrm{C}\right]-(+)$-PHNO binding and impulsivity in $\mathrm{AD}$ [72-75]. This suggests that the nature of impulsivity in $\mathrm{AD}$ may differ from cocaine and gambling disorders.

An exploratory analysis found that higher levels of depressive symptoms (BDI score) were associated with a blunted endogenous opioid release in the amygdala, although this result does not survive a strict Bonferroni correction for multiple correlations. The amygdala is an important region for emotional processing in depression 
[76], and endogenous opioid release in the amygdala is associated with positive emotion and exercise-induced negative emotion, and is dysregulated in major depressive disorder [48, 77-79]. One reason for this association being observed only in alcohol-dependent participants may be due to a higher and greater range of BDI scores compared with controls. These scores were, however, low and did not reach a threshold for clinically significant depression.

Our study was designed to be adequately powered for our primary outcome of $\left[{ }^{11} \mathrm{C}\right]$ carfentanil $\triangle \mathrm{BP}_{\mathrm{ND}}$ and our samples size is consistent with those in other relevant published human PET literature examining amphetamineinduced endogenous neurotransmitter release $[15,26,27$, $50,52,80]$. Our study sample size is too small to adequately investigate clinical factors that may be associated with our PET outcome measures.

In summary, we have demonstrated for the first time blunted dexamphetamine-induced opioid release in the brain in abstinent alcohol-dependent individuals. This study adds to the evidence supporting a role for a dysregulated opioid system in $\mathrm{AD}$ and builds on our previous study with the same protocol in gambling disorder showing similarly blunted dexamphetamine-induced opioid release in the presence of 'normal' MOR availability. The similarly blunted opioid release in gambling disorder where participants had no history of substance dependence, excluding nicotine, lends further support to an 'opioid deficit' contributing to vulnerability to addiction. Thus, dysregulated opioid signalling appears to be a common feature across both behavioural and substance addictions.

Further characterisation of the endogenous opioid tone and the dopamine-opioid interactions will inform our understanding of substance and behavioural addictions and how best to optimise and develop the use of opioid antagonists in treatment.

Acknowledgements We wish to thank the study participants and the clinical team at Imanova, Centre for Imaging Sciences. This article presents independent research funded by the Medical Research Council (Grant G1002226) and Imperial College BRC and supported by the NIHR Imperial Clinical Research Facility at Imperial College Healthcare NHS Trust. The views expressed are those of the authors and not necessarily those of the Medical Research Council, Imperial College BRC, the NHS, the NIHR or the Department of Health.

\section{Compliance with ethical standards}

Conflict of interest Professor Lingford-Hughes has received honoraria paid into her institutional funds for speaking and chairing engagements from Lundbeck, Lundbeck Institute UK and Janssen-Cilag. She has received research support from Lundbeck and has been consulted by but received no monies from Britannia Pharmaceuticals. Professor Nutt has consulted for, or received speaker's fees, or travel or grant support from the following companies with an interest in the treatment of addiction: RB pharmaceuticals, Lundbeck, GSK, Pfizer, D\&A Pharma, Nalpharm,
Opiant Pharmaceutical and Alkermes. Professor Gunn is a consultant for Abbvie and Cerveau. Dr Rabiner is a consultant for Opiant Pharmaceutical, AbbVie, Teva, and a shareholder in GSK. Professor Waldman has received honoraria from Bayer, Novartis, and GSK, and has been a consultant for Bayer.

Open Access This article is licensed under a Creative Commons Attribution 4.0 International License, which permits use, sharing, adaptation, distribution and reproduction in any medium or format, as long as you give appropriate credit to the original author(s) and the source, provide a link to the Creative Commons license, and indicate if changes were made. The images or other third party material in this article are included in the article's Creative Commons license, unless indicated otherwise in a credit line to the material. If material is not included in the article's Creative Commons license and your intended use is not permitted by statutory regulation or exceeds the permitted use, you will need to obtain permission directly from the copyright holder. To view a copy of this license, visit http://creativecommons. org/licenses/by/4.0/.

\section{References}

1. World Health Organisation. Global status report on alcohol and health 2014: 1-392.

2. Sacks JJ, Gonzales KR, Bouchery EE, Tomedi LE, Brewer RD. 2010 national and state costs of excessive alcohol consumption. Am J Prev Med. 2015;49:e73-9.

3. Anderson P, Baumberg B. Alcohol in Europe - public health perspective: report summary. Drugs Educ Prev Policy. 2006;13:483-8.

4. Miller WR, Walters ST, Bennett ME. How effective is alcoholism treatment in the United States? J Stud Alcohol. 2001;62:211-20.

5. Lingford-Hughes A, Welch S, Peters L, Nutt D. BAP updated guidelines: evidence-based guidelines for the pharmacological management of substance abuse, harmful use, addiction and comorbidity: recommendations from BAP. J Psychopharmacol. 2012;26:899-952.

6. NHS NI for H and CE. Alcohol-use disorders: diagnosis, assessment and management of harmful drinking and alcohol dependence. National Collaborating Centre for Mental Health. Leicester (UK): British Psychological Society; 2011:1-51.

7. Rösner S, Hackl-Herrwerth A, Leucht S, Vecchi S, Srisurapanont M, Soyka M. Opioid antagonists for alcohol dependence. Chichester, UK: John Wiley \& Sons, Ltd; 2010. doi:10.1002/ 14651858.CD001867.pub3.

8. Anton RF, Moak DH, Waid LR, Latham PK, Malcolm RJ, Dias JK. Naltrexone and cognitive behavioral therapy for the treatment of outpatient alcoholics: results of a placebo-controlled trial a few well-controlled clinical trials with limited. Am J Psychiatry. 1999;156:1758-64.

9. Chick J, Anton R, Checinski K, Croop R, Drummond DC, Farmer $\mathrm{R}$, et al. A multicentre, randomized, double-blind, placebocontrolled trial of naltrexone in the treatment of alcohol dependence or abuse. Alcohol Alcohol. 2000;35:587-93.

10. Myrick H, Anton RF, Li X, Henderson S, Randall PK, Voronin K, et al. Effect of naltrexone and ondansetron on alcohol cue-induced activation of the ventral striatum in alcoholdependent people. Arch Gen Psychiatry. 2008;65:466.

11. Quelch DR, Mick I, McGonigle J, Ramos AC, Flechais RSA, Bolstridge $\mathrm{M}$, et al. Nalmefene reduces reward anticipation in alcohol dependence: an experimental functional magnetic resonance imaging study. Biol Psychiatry. 2017;81:941-8.

12. Peciña S. Opioid reward 'liking' and 'wanting' in the nucleus accumbens. Physiol Behav. 2008;94:675-80. 
13. Berridge $\mathrm{KC}$, Kringelbach ML. Pleasure systems in the brain. Neuron. 2015;86:646-64.

14. Le Merrer J, Becker JAJ, Befort K, Kieffer BL. Reward processing by the opioid system in the brain. Physiol Rev. 2009;89:1379-412.

15. Colasanti A, Searle GE, Long CJ, Hill SP, Reiley RR, Quelch D, et al. Endogenous opioid release in the human brain reward system induced by acute amphetamine administration. Biol Psychiatry. 2012;72:371-7.

16. Mitchell JM, O’Neil JP, Janabi M, Marks SM, Jagust WJ, Fields HL. Alcohol consumption induces endogenous opioid release in the human orbitofrontal cortex and nucleus accumbens. Sci Transl Med. 2012;4:116ra6

17. Jayaram-Lindström N, Wennberg P, Hurd YL, Franck J. Effects of naltrexone on the subjective response to amphetamine in healthy volunteers. J Clin Psychopharmacol. 2004;24:665-9.

18. McCaul M, Wand GS, Eissenberg T, Rohde CA, Cheskin LJ, Naltrexone alters subjective and psychomotor responses to alcohol in heavy drinking subjects. Neuropsychopharmacology. 2000; 22:480-92.

19. Davidson D, Palfai T, Bird C, Swift R. Effects of naltrexone on alcohol self-administration in heavy drinkers. Alcohol Clin Exp Res. 1999;23:195-203.

20. Ulm RR, Volpicelli JR, Volpicelli LA. Opiates and alcohol self-administration in animals. J Clin Psychiatry. 1995; 56:5-14.

21. Oswald L, Wand G. Opioids and alcoholism. Physiol Behav. 2004;81:339-58.

22. Williams TM, Davies SJC, Taylor LG, Daglish MRC, Hammers A, Brooks DJ, et al. Brain opioid receptor binding in early abstinence from alcohol dependence and relationship to craving: An [11C]diprenorphine PET study. Eur Neuropsychopharmacol. 2009;19:740-8.

23. Heinz A, Reimold M, Wrase J, Hermann D, Croissant B, Mundle $\mathrm{G}$, et al. Correlation of stable elevations in striatal $\mu$-opioid receptor availability in detoxified alcoholic patients with alcohol craving. Arch Gen Psychiatry. 2005;62:57.

24. Weerts EM, Wand GS, Kuwabara H, Munro CA, Dannals RF, Hilton J, et al. Positron emission tomography imaging of $\mathrm{Mu}$ - and delta-opioid receptor binding in alcohol-dependent and healthy control subjects. Alcohol Clin Exp Res. 2011;35:2162-73.

25. Hermann D, Hirth N, Reimold M, Batra A, Smolka MN, Hoffmann $\mathrm{S}$, et al. Low $\mu$-opioid receptor status in alcohol dependence identified by combined positron emission tomography and post-mortem brain analysis. Neuropsychopharmacology. 2017;42:606-14.

26. Mick I, Myers J, Stokes PRA, Erritzoe D, Colasanti A, BowdenJones $\mathrm{H}$, et al. Amphetamine induced endogenous opioid release in the human brain detected with [11C]carfentanil PET: replication in an independent cohort. Int $\mathrm{J}$ Neuropsychopharmacol. 2014;17:2069-74.

27. Mick I, Myers J, Ramos AC, Stokes PR, Erritzoe D, Colasanti A, et al. Blunted endogenous opioid release following an oral amphetamine challenge in pathological gamblers. Neuropsychopharmacology. 2016;41:1742-50.

28. Stockwell T, Hodgson R, Edwards G, Taylor C, Rankin H. The development of a questionnaire to measure severity of alcohol dependence. Addiction. 1979;74:79-87.

29. Adinoff B, Talmadge C, Williams MJ, Schreffler E, Jackley PK, Krebaum SR. Time to relapse questionnaire (TRQ): a measure of sudden relapse in substance dependence. Am J Drug Alcohol Abus. 2010;36:140-9.

30. Bohn MJ, Krahn DD, Staehler BA. Development and initial validation of a measure of drinking urges in abstinent alcoholics. Alcohol Clin Exp Res. 1995;19:600-6.

31. Witkiewitz K, Hallgren KA, Kranzler HR, Mann KF, Hasin DS, Falk DE, et al. Clinical validation of reduced alcohol consumption after treatment for alcohol dependence using the world health organization risk drinking levels. Alcohol Clin Exp Res. 2017;41:179-86.

32. Sheehan DV, Lecrubier Y, Sheehan KH, Amorim P, Janavs J, Weiller E, et al. The Mini-International Neuropsychiatric Interview (M.I.N.I.): the development and validation of a structured diagnostic psychiatric interview for DSM-IV and ICD-10. J Clin Psychiatry. 1998;59:22-33.

33. Beck A, Steer R, Brown G. Beck Depression Inventory II manual, 1996.

34. Spielberger C. Manual for the State-Trait Anxiety Inventory (STAI). Consult Psychol Press 1983: 4-26.

35. Cyders MA, Smith GT, Spillane NS, Fischer S, Annus AM, Peterson C. Integration of impulsivity and positive mood to predict risky behavior: Development and validation of a measure of positive urgency. Psychol Assess. 2007;19:107-18.

36. Van Kammen DP, Murphy DL. Attenuation of the euphoriant and activating effects of $\mathrm{d}$ - and 1-amphetamine by lithium carbonate treatment. Psychopharmacologia. 1975;44:215-24.

37. McGonigle J, Murphy A, Paterson LM, Reed LJ, Nestor L, Nash $\mathrm{J}$, et al. The ICCAM platform study: an experimental medicine platform for evaluating new drugs for relapse prevention in addiction. J Psychopharmacol. 2017;31:3-16.

38. Paterson LM, Flechais RS, Murphy A, Reed LJ, Abbott S, Boyapati $\mathrm{V}$, et al. The Imperial College Cambridge Manchester (ICCAM) platform study: An experimental medicine platform for evaluating new drugs for relapse prevention in addiction. Part A: study description. J Psychopharmacol. 2015;29:943-60.

39. Tziortzi AC, Searle GE, Tzimopoulou S, Salinas C, Beaver JD, Jenkinson $\mathrm{M}$, et al. Imaging dopamine receptors in humans with [11C]-(+)-PHNO: dissection of D3 signal and anatomy. Neuroimage. 2011;54:264-77.

40. Lammertsma AA, Hume SP. Simplified reference tissue model for PET receptor studies. Neuroimage. 1996;4:153-8.

41. Innis RB, Cunningham VJ, Delforge J, Fujita M, Gjedde A, Gunn $\mathrm{RN}$, et al. Consensus nomenclature for in vivo imaging of reversibly binding radioligands. J Cereb Blood Flow Metab. 2007;27:1533-9.

42. Weerts EM, Kim YK, Wand GS, Dannals RF, Lee JS, Frost JJ, et al. Differences in $\delta$ - and $\mu$-opioid receptor blockade measured by positron emission tomography in naltrexone-treated recently abstinent alcohol-dependent subjects. Neuropsychopharmacology. 2008;33:653-65.

43. Nestor LJ, Murphy A, McGonigle J, Orban C, Reed L, Taylor E et al. Acute naltrexone does not remediate fronto-striatal disturbances in alcoholic and alcoholic polysubstance-dependent populations during a monetary incentive delay task. Addict Biol. 22:1576-89.

44. Murphy A, Nestor LJ, McGonigle J, Paterson L, Boyapati V, Ersche KD, et al. Acute D3 antagonist GSK598809 selectively enhances neural response during monetary reward anticipation in drug and alcohol dependence. Neuropsychopharmacology. 2017;42:1049-57.

45. Koob GF, Le Moal M. Addiction and the brain antireward system. Annu Rev Psychol. 2008;59:29-53.

46. Dai X, Thavundayil J, Gianoulakis C. Differences in theperipheral levels of $\beta$-endorphin in response to alcohol and stress as a function of alcohol dependence and family history of alcoholism. Alcohol Clin Exp Res. 2005;29:1965-75.

47. Goldfarb AH, Jamurtas AZ. $\beta$-endorphin response to exercise. Sport Med. 1997;24:8-16.

48. Saanijoki T, Tuominen L, Tuulari JJ, Nummenmaa L, Arponen E, Kalliokoski K, et al. Opioid Release after High-Intensity Interval Training in Healthy Human Subjects. Neuropsychopharmacology. 2018;43:246-54. 
49. Cohen MR, Nurnberger JI, Pickar D, Gershon E, Bunney WE. Dextroamphetamine infusions in normals result in correlated increases of plasma $\beta$-endorphin and cortisol immunoreactivity. Life Sci. 1981;29:1243-7.

50. Martinez D, Gil R, Slifstein M, Hwang DR, Huang Y, Perez A, et al. Alcohol dependence is associated with blunted dopamine transmission in the ventral striatum. Biol Psychiatry. 2005;58:779-86.

51. Oswald LM, Wong DF, McCaul M, Zhou Y, Kuwabara H, Choi $\mathrm{L}$, et al. Relationships among ventral striatal dopamine release, cortisol secretion, and subjective responses to amphetamine. Neuropsychopharmacology. 2005;30:821-32.

52. Boileau I, Payer D, Chugani B, Lobo DSS, Houle S, Wilson AA, et al. In vivo evidence for greater amphetamine-induced dopamine release in pathological gambling: a positron emission tomography study with [11C]-(+)-PHNO. Mol Psychiatry. 2014;19:1305-13.

53. Drevets WC, Gautier C, Price JC, Kupfer DJ, Kinahan PE, Grace AA, et al. Amphetamine-induced dopamine release in human ventral striatum correlates with euphoria. Biol Psychiatry. 2001;49:81-96.

54. Jayaram-Lindström N, Guterstam J, Häggkvist J, Ericson M, Malmlöf T, Schilström B, et al. Naltrexone modulates dopamine release following chronic, but not acute amphetamine administration: a translational study. Transl Psychiatry. 2017;7:e1104.

55. Guterstam J, Jayaram-Lindström N, Cervenka S, Frost JJ, Farde L, Halldin C, et al. Effects of amphetamine on the human brain opioid system--a positron emission tomography study. Int $\mathrm{J}$ Neuropsychopharmacol. 2013;16:763-9.

56. Olive MF, Koenig HN, Nannini MA, Hodge CW. Stimulation of endorphin neurotransmission in the nucleus accumbens by ethanol, cocaine, and amphetamine. J Neurosci. 2001;21:RC184.

57. Quelch DR, Katsouri L, Nutt DJ, Parker CA, Tyacke RJ. Imaging endogenous opioid peptide release with [11C]carfentanil and [3H] diprenorphine: influence of agonist-induced internalization. J Cereb Blood Flow Metab. 2014;34:1604-12.

58. Ciliax BJ, Drash GW, Staley JK, Haber S, Mobley CJ, Miller GW, et al. Immunocytochemical localization of the dopamine transporter in human brain. J Comp Neurol. 1999;409:38-56.

59. Lubman D, Allen N, Peters L, Deakin J. Electrophysiological evidence that drug cues have greater salience than other affective stimuli in opiate addiction. J Psychopharmacol. 2008;22:836-42.

60. Koob GF, Volkow ND. Neurobiology of addiction: a neurocircuitry analysis. Lancet Psychiatry. 2016;3:760-73.

61. Andrews MM, Meda SA, Thomas AD, Potenza MN, Krystal JH, Worhunsky P, et al. Individuals family history positive for alcoholism show functional magnetic resonance imaging differences in reward sensitivity that are related to impulsivity factors. Biol Psychiatry. 2011;69:675-83.

62. Wrase J, Schlagenhauf F, Kienast T, Wüstenberg T, Bermpohl F, Kahnt $\mathrm{T}$, et al. Dysfunction of reward processing correlates with alcohol craving in detoxified alcoholics. Neuroimage. 2007;35:787-94.

63. Schacht JP, Anton RF, Myrick H. Functional neuroimaging studies of alcohol cue reactivity: a quantitative meta-analysis and systematic review. Addict Biol. 2013;18:121-33.

64. Schacht JP, Randall PK, Latham PK, Voronin KE, Book SW, Myrick $\mathrm{H}$, et al. Predictors of naltrexone response in a randomized trial: reward-related brain activation, OPRM1 genotype, and smoking status. Neuropsychopharmacology. 2017; 42:2640-53.

65. Tuulari JJ, Tuominen L, de Boer FE, Hirvonen J, Helin S, Nuutila $\mathrm{P}$, et al. Feeding releases endogenous opioids in humans. J Neurosci. 2017;37:8284-91.
66. Pennock RL, Hentges ST. Differential expression and sensitivity of pre- and postsynaptic opioid receptors regulating hypothalamic proopiomelanocortin neurons. J Neurosci. 2011;31:281-8.

67. Nuechterlein EB, Ni L, Domino EF, Zubieta J-K. Nicotinespecific and non-specific effects of cigarette smoking on endogenous opioid mechanisms. Prog Neuro-Psychopharmacol Biol Psychiatry. 2016;69:69-77.

68. Scott DJ, Domino EF, Heitzeg MM, Koeppe RA, Ni L, Guthrie S, et al. Smoking modulation of $\mu$-opioid and dopamine D2 receptormediated neurotransmission in humans. Neuropsychopharmacology. 2007;32:450-7.

69. Kuwabara H, Heishman SJ, Brasic JR, Contoreggi C, Cascella N, Mackowick KM, et al. Mu opioid receptor binding correlates with nicotine dependence and reward in smokers. PLOS ONE. 2014;9: e113694.

70. Weerts EM, McCaul ME, Kuwabara H, Yang X, Xu X, Dannals $\mathrm{RF}$, et al. Influence of OPRM1 Asn40Asp variant (A118G) on [11C]carfentanil binding potential: preliminary findings in human subjects. Int J Neuropsychopharmacol 2013; 16:47-53.

71. Peciña M, Love T, Stohler CS, Goldman D, Zubieta J-K. Effects of the Mu opioid receptor polymorphism (OPRM1 A118G) on pain regulation, placebo effects and associated personality trait measures. Neuropsychopharmacology. 2015;40:957-65.

72. Erritzoe D, Tziortzi A, Bargiela D, Colasanti A, Searle GE, Gunn RN, et al. In vivo imaging of cerebral dopamine D3 receptors in alcoholism. Neuropsychopharmacology. 2014; 39:1703-12.

73. Clark L, Stokes PR, Wu K, Michalczuk R, Benecke A, Watson $B J$, et al. Striatal dopamine $D_{2} / D_{3}$ receptor binding in pathological gambling is correlated with mood-related impulsivity. Neuroimage. 2012;63:40-6.

74. Boileau I, Payer D, Chugani B, Lobo D, Behzadi A, Rusjan PM, et al. The D2/3 dopamine receptor in pathological gambling: a positron emission tomography study with [11C]-(+)-propyl-hexahydro-naphtho-oxazin and [11C]raclopride. Addiction. 2013;108:953-63.

75. Payer DE, Behzadi A, Kish SJ, Houle S, Wilson AA, Rusjan PM, et al. Heightened D3 dopamine receptor levels in cocaine dependence and contributions to the addiction behavioral phenotype: a positron emission tomography study with [11C]-+ -PHNO. Neuropsychopharmacology. 2014;39:311-8.

76. Siegle GJ, Steinhauer SR, Thase ME, Stenger VA, Carter CS. Can't shake that feeling: event-related fMRI assessment of sustained amygdala activity in response to emotional information in depressed individuals. Biol Psychiatry. 2002;51:693-707.

77. Koepp M, Hammers A, Lawrence A, Asselin M, Grasby P, Bench C. Evidence for endogenous opioid release in the amygdala during positive emotion. Neuroimage. 2009;44:252-6.

78. Kennedy SE, Koeppe RA, Young EA, Zubieta J-K, W C, A R, et al. Dysregulation of endogenous opioid emotion regulation circuitry in major depression in women. Arch Gen Psychiatry. 2006;63:1199.

79. Hsu DT, Sanford BJ, Meyers KK, Love TM, Hazlett KE, Walker SJ, et al. It still hurts: altered endogenous opioid activity in the brain during social rejection and acceptance in major depressive disorder. Mol Psychiatry. 2015;20:193-200.

80. Shotbolt P, Tziortzi AC, Searle GE, Colasanti A, van der Aart J, Abanades S, et al. Within-subject comparison of [(11)C]-(+)PHNO and [(11)C]raclopride sensitivity to acute amphetamine challenge in healthy humans. J Cereb Blood Flow Metab. 2012;32:127-36. 